\title{
Molecular mechanism underlying the anti- inflammatory effects of volatile components of Ligularia fischeri (Ledeb) Turcz based on network pharmacology
}

Xulong Huang ${ }^{1}$, Yuan $\mathrm{GaO}^{2}$, Feng Xu' ${ }^{1}$, Dongsheng Fan ${ }^{3}$, Yuqing Liang ${ }^{4}$, Xiangpei Wang ${ }^{1 *}$ and Hongmei Wu ${ }^{1 *}$ (D)

\begin{abstract}
Background: Ligularia fischeri (Ledeb) Turcz (LFT) is a well-known expectorant and active anti-inflammatory agent in Chinese traditional medicine. LFT's expectorant effect is closely related to its anti-inflammatory effects. This study aimed to evaluate the differential composition and anti-inflammatory mechanisms of the volatile components in LFT from different production areas.

Method: Headspace solid-phase microextraction-gas chromatography-mass spectrometry analysis of volatile components, as well as chemometric methods, including similarity analysis, hierarchical clustering analysis, and principal component analysis, were performed to identify LFT produced in different areas. The molecular mechanism underlying the anti-inflammatory effects of these components was determined by network pharmacology analysis.
\end{abstract}

Results: We observed significant differences in the chemical constituents and percentage contents in samples with different origins. Eighteen volatile components were identified in four different producing areas, among which the highest content of olefinic components was the main component of the aroma of LFT. The mechanisms of these pharmacological effects involved multiple targets and pathways. Twenty-seven potential target proteins and 65 signaling pathways were screened, and a "component-target-disease" interaction network map was constructed. The volatile components of the LFT function mainly by inhibiting the production of inflammatory factors.

Conclusion: This study provides a theoretical framework for further development and application of LFT used in traditional Chinese medicine.

Keywords: Ligularia fischeri (Ledeb) Turcz, Headspace solid-phase microextraction-gas chromatography-mass spectrometry, Anti-inflammatory, Molecular mechanism, Volatile components, Network pharmacology, Chemometric methods

\footnotetext{
*Correspondence: wxp0123@126.com; whm0425@126.com

'Department of Pharmacy, Guizhou University of Traditional Chinese

Medicine, Guiyang City, Guizhou Province, Guiyang 550002, People's Republic of China

Full list of author information is available at the end of the article
}

(C) The Author(s). 2020 Open Access This article is licensed under a Creative Commons Attribution 4.0 International License, which permits use, sharing, adaptation, distribution and reproduction in any medium or format, as long as you give appropriate credit to the original author(s) and the source, provide a link to the Creative Commons licence, and indicate if changes were made. The images or other third party material in this article are included in the article's Creative Commons licence, unless indicated otherwise in a credit line to the material. If material is not included in the article's Creative Commons licence and your intended use is not permitted by statutory regulation or exceeds the permitted use, you will need to obtain permission directly from the copyright holder. To view a copy of this licence, visit http://creativecommons.org/licenses/by/4.0/ The Creative Commons Public Domain Dedication waiver (http://creativecommons.org/publicdomain/zero/1.0/) applies to the data made available in this article, unless otherwise stated in a credit line to the data. 


\section{Background}

Radix et Rhizoma Ligularia fischeri (Ledeb) Turcz (LFT) is a perennial herbaceous plant that grows at $1400-3300$ $\mathrm{m}$ above sea level by rivers, on hillsides, and in forests [1]. LFT has antibacterial and anti-inflammatory effects, resolves phlegm, relieves cough, activates blood circulation, and alleviates pain, among other effects. LFT is mainly used to treat coughs, ulcers, and tuberculosis as a clinical therapeutic agent [2]. The chemical constituents and pharmacological effects of LFT have been studied previously [3-7]. The plant roots are rich in aroma and volatile oils. Volatile oil components in the flowers and leaves have also been observed following steam distillation [810]. However, no studies have evaluated volatile oils in the roots by headspace solid-phase microextraction (HSSPME). Compared to steam distillation, SPME is simple, fast, and inexpensive; it does not require solvents or cause environmental pollution. Automation is simple, and this method can be used with electrophoresis and other highefficiency separation and analysis techniques [11]. Volatile oils are widely used in spice, food, and cosmetic production and have been shown to have antibacterial, antioxidant, and anti-inflammatory activities [12].

The ethyl acetate extract and ethanol extract of LFT show potent anti-inflammatory activity [13, 14]. Inflammation is a series of defensive responses produced by various injury factors. The inflammatory response is a complex process induced by events such as bacterial infection and chemical damage that can lead to cell injury or death. This mechanism induces the ultimate release of tumor necrosis factor (TNF)- $\alpha$, interleukin (IL)-6, and other inflammatory factors from leukocytes and monocyte macrophages [15, 16]. Chronic or excessive inflammation is closely related to the pathogenesis of several diseases, including arthritis, and cardiovascular disease, among other diseases [17-19]. However, few studies have evaluated the mechanism underlying LFT's anti-inflammatory effects at the cellular and molecular levels. Recent studies showed that the integrity and systematic nature of network pharmacology coincide with the synergistic effect of "multi-component, multi-channel, and multi-target" of traditional Chinese medicine. This analogy provides a new perspective for studying complex systems affected by traditional Chinese medicine [20]. Therefore, the molecular mechanism of the anti-inflammatory effects of LFT volatile oil could be evaluated by network pharmacology.

Here, volatile oils were extracted from LFT root collected from Guizhou Province by HS-SPME. The volatile components of LFT were identified by gas chromatography-mass spectrometry (GC-MS). The percentage content of volatile components was calculated using the peak area normalization method, and the content was analyzed by chemometric methods, including similarity analysis, hierarchical clustering analysis, and principal component analysis. We constructed a complex network of "component-target-disease" based on molecular docking and network pharmacology. The anti-inflammatory targets and signaling pathways of the volatile components of LFT were preliminarily determined. We explored the effect of the production area on LFT quality and provided a reference for determining the molecular mechanism of the anti-inflammatory effects of volatile components in LFT.

\section{Methods}

\section{HS-SPME-GC-MS}

Plant samples

Ligularia fischeri (Ledeb) Turcz samples of different areas in Guizhou Province (China) were obtained from the wild, Table 1 shows volatile components $(\mathrm{m} / \mathrm{z})$ and percentage content (\%) of LFT, and no permissions were required to collect such samples. The geographical coordinates of collection sites of the samples are E105.915021 and N26.689198 (Dafang County, Bijie City), E106.450493 and N26. 216,903 (Longli County, Duyun City), E106.620265 and N25.868643 (Pingba County, Anshun City), E105.950493 and N25.761690 (Leishan County, Kaili City), respectively. The authors comply with the Convention on the Trade in Endangered Species of Wild Fauna and Flora. All samples were identified by Prof. X.P. WANG (XiangPei WANG), Department of Pharmacognosy Guizhou University of Traditional Chinese Medicine, China, and stored in a cool, dry place. All voucher specimens have been deposited in a publicly available herbarium, Guizhou University of Traditional Chinese Medicine, Guizhou, China.

\section{SPME fibers}

The SPME fibers, including $85 \mu \mathrm{m}$ Carboxen (CAR)/poly dimethysiloxane (PDMS), $65 \mu \mathrm{m}$ PDMS/divinylbenzene (DVB), $85 \mu \mathrm{m}$ polyacrylate and $50 / 30 \mu \mathrm{m}$ DVB/CAR/ PDMS, were purchased from Supelco (Bellefonte, PA, USA). The TRIPLUS (RSH) headspace sampler was purchased from Thermo Fisher Scientific (Waltham, MA, USA). The muffle furnace (P330) was purchased from Nabore Co., Ltd. (Nabertherm, Germany).

\section{Extraction of volatile components by headspace SPME}

All samples were crushed and sifted through 40 mesh; 1.0 g sample was packed into a $5 \mathrm{~mL}$ extraction bottle. Next, $50 / 30 \mu \mathrm{m}$ DVB/CAR/PDMS extraction fiber head, which had been activated for $5 \mathrm{~min}$ was inserted into the bottle and incubated for $10 \mathrm{~min}$ at $100{ }^{\circ} \mathrm{C}$. The extraction head was extracted by headspace extraction for $40 \mathrm{~min}$, then extraction head was immediately inserted into the injection port of the gas chromatograph (temperature $220^{\circ} \mathrm{C}$ ) and desorbed for $5 \mathrm{~min}$. 
Table 1 Volatile components (m/z) and percentage content (\%) of LFT roots

\begin{tabular}{|c|c|c|c|c|c|c|c|c|}
\hline \multirow[t]{2}{*}{ NO. } & \multirow{2}{*}{$\begin{array}{l}\text { Retention } \\
\text { time } \\
\text { (min) }\end{array}$} & \multirow[t]{2}{*}{ Name of compound } & \multirow{2}{*}{$\begin{array}{l}\text { Molecular } \\
\text { formula }\end{array}$} & \multirow{2}{*}{$\begin{array}{l}\text { Molecular } \\
\text { weight }\end{array}$} & \multicolumn{4}{|c|}{ Percentage content (\%) } \\
\hline & & & & & Bijie City & Duyun City & Anshun City & Kaili City \\
\hline 1 & 9.2 & alpha-Pinene & $\mathrm{C} 10 \mathrm{H} 16$ & 136 & - & 0.77 & - & 0.73 \\
\hline 2 & 10.57 & beta-Pinene & $\mathrm{C} 10 \mathrm{H} 16$ & 136 & - & 2.02 & 2.07 & 1.67 \\
\hline 3 & 12.03 & O-CYMENE & $\mathrm{C} 10 \mathrm{H} 14$ & 134 & 2.37 & 3.45 & 7.13 & 3.38 \\
\hline 4 & 12.23 & SABINENE & $\mathrm{C} 10 \mathrm{H} 16$ & 136 & - & 2.53 & - & - \\
\hline 5 & 12.65 & 4-Methylstyrene & $\mathrm{C} 9 \mathrm{H} 10$ & 118 & 3.33 & 0.7 & 5.08 & 6.17 \\
\hline 6 & 12.71 & beta-Ocimene & $\mathrm{C} 10 \mathrm{H} 16$ & 136 & - & 1.01 & - & - \\
\hline 7 & 13.93 & Terpinolene & $\mathrm{C} 10 \mathrm{H} 16$ & 136 & - & - & - & 0.67 \\
\hline 8 & 18.15 & $\begin{array}{l}\text { Benzene, 2-methoxy- 4-methyl-1- } \\
\text { (1-methylethyl) }\end{array}$ & $\mathrm{C} 11 \mathrm{H} 16 \mathrm{O}$ & 164 & - & - & 1.62 & 3.71 \\
\hline 9 & 18.71 & Linalyl acetate & $\mathrm{C} 12 \mathrm{H} 20 \mathrm{O} 2$ & 196 & - & - & - & 1.21 \\
\hline 10 & 21.39 & 4-Terpinyl acetate & $\mathrm{C} 12 \mathrm{H} 20 \mathrm{O} 2$ & 196 & - & - & - & 0.73 \\
\hline 11 & 23.38 & Caryophyllene & $\mathrm{C} 15 \mathrm{H} 24$ & 204 & 2.47 & 1.46 & 1.66 & 2.26 \\
\hline 12 & 24.29 & Humulene & $\mathrm{C} 15 \mathrm{H} 24$ & 204 & - & - & - & 1.17 \\
\hline 13 & 25.09 & EREMOPHILENE & $\mathrm{C} 15 \mathrm{H} 24$ & 204 & 7.3 & 11.21 & 16.60 & - \\
\hline 14 & 25.41 & FARNESENE & $\mathrm{C} 15 \mathrm{H} 24$ & 204 & - & 0.88 & 4.73 & 8.47 \\
\hline 15 & 25.81 & (-)-ISOLEDENE & $\mathrm{C} 15 \mathrm{H} 24$ & 204 & 2.18 & 0.64 & - & 0.82 \\
\hline 16 & 29.41 & ATRACTYLINE (DISCONTINUED)(SH) & $\mathrm{C} 15 \mathrm{H} 20 \mathrm{O}$ & 216 & - & 0.78 & - & - \\
\hline 17 & 32.43 & Dodecanal & $\mathrm{C} 12 \mathrm{H} 24 \mathrm{O}$ & 184 & - & - & - & 1.25 \\
\hline 18 & 33.74 & 1-Hexadecanol & $\mathrm{C} 16 \mathrm{H} 34 \mathrm{O}$ & 242 & 4.99 & - & 2.32 & 5.37 \\
\hline
\end{tabular}

Note: - indicates undetected components

\section{GC-MS analysis}

Analyses were carried out with a Thermo Fisher Scientific GC system (TRACE1310) coupled to an ISQLT mass spectrometer. The volatile compounds were separated on a TG-5SilMS capillary column $(30 \mathrm{~m} \times 0.25$ $\mathrm{mm}$, and $0.25 \mu \mathrm{m}$ film thickness). The carrier gas was helium with a column-head pressure of 10 psi. The oven temperature was held at $50{ }^{\circ} \mathrm{C}$ and for $5 \mathrm{~min}$, increased to $300^{\circ} \mathrm{C}$ at a rate of $5{ }^{\circ} \mathrm{C} / \mathrm{min}$, and then held for $5 \mathrm{~min}$. The flow rate was $1 \mathrm{~mL} / \mathrm{min}$. The injection temperature was $220^{\circ} \mathrm{C}$ at splitless injection. A full scan mode $(\mathrm{m} / \mathrm{z}$ 35-350) was applied to identify all target compounds. The ion source temperature was $280^{\circ} \mathrm{C}$ with an ionizing energy of $70 \mathrm{eV}$. Peaks were identified by comparison of their mass spectra with those of the Nist2005 and Wiley275 library, and the percentage of each compound was calculated by a normalization method.

\section{Network pharmacology}

\section{Molecular structure and retrieval of target proteins}

The molecular structures of the volatile compounds were obtained from the PubChem database (https://pubchem. ncbi.nlm.nih.gov/), and the 3D structures were downloaded in .sdf format. The target proteins of these components were predicted using the BATMAN-TCM (a Bioinformatics Analysis Tool for Molecular mechANism of Traditional Chinese Medicine) database (http://bionet. ncpsb.org/batman-tcm/index.php/Home/Index/index).

The target proteins corresponding to volatile components were screened according to a cutoff score of $\geq 48$ and a $P$ value of $\leq 0.01$. Inflammation-related target proteins were retrieved from a comprehensive database of human genes and gene phenotypes (OMIM, http://www.omim.org/). Finally, the screened targets were converted into UniProt ID format with the UniProt database.

\section{Network construction and analysis}

These components, target proteins, and interactive proteins were connected as a "component-target-disease" network by protein-protein interaction (http://www.genome. $\mathrm{jp} / \mathrm{kegg} /$ ). The network was visually analyzed using Cytoscape 3.6.1 software. The topology parameters of degree, betweenness centrality, and closeness centrality for each node were evaluated with CentiScaPe1.2. Proteins showing values greater than the median value for the above three topological parameters at all nodes was regarded as a potential target of the anti-inflammatory response. The anti-inflammatory affinity of these targets was evaluated by molecular docking analysis. Protein interaction analysis of the selected targets was carried out using the STRING database (https://string-db.org/). 
Gene ontology (GO) and KEGG enrichment analysis

Potential targets were screened by the KEGG pathway and GO biological process analysis using the DAVID (https://david.ncifcrf.gov/) database. $P$-values $(P<0.05)$ were considered as statistically significant, with a smaller $\mathrm{P}$-value indicating a more significant correlation. The potential targets were marked on signaling pathways closely related to inflammation using the KEGG Mapper function in the KEGG (https://www.genome.jp/kegg/) signaling pathway database.

\section{Molecular docking}

Molecular docking was performed using the SystemsDock website, which is a database for network pharmacologybased prediction and analysis. This site applies highprecision docking simulation, and molecular pathway maps to comprehensively characterize ligand selectivity and illustrate how a ligand acts on a complex molecular network.

\section{Data analysis}

Data analysis was performed with the Nist2005 and Wiley275 library. Cluster analysis was carried out using SPSS 20.0 statistical software (SPSS, Inc., Chicago, IL, USA). Principal components analysis (PCA) was performed using SIMCA 14. 0 software from Umetrics, Inc. (San Jose, CA, USA).

\section{Results}

\section{Identification and analysis of volatile components}

The total ion chromatogram (TIC) was obtained by evaluating the volatile components in LFT from different producing areas. The results are shown in Fig. 1. The peaks in the TIC were retrieved by mass spectrometry and identified by comparison with standards in the Nist2005 and Wiley275 databases. The percentage content of each compound was calculated according to the peak area normalization method. The results are shown in Table 1. A total of 18 components were identified in LFT from these areas. There were three common components: O-

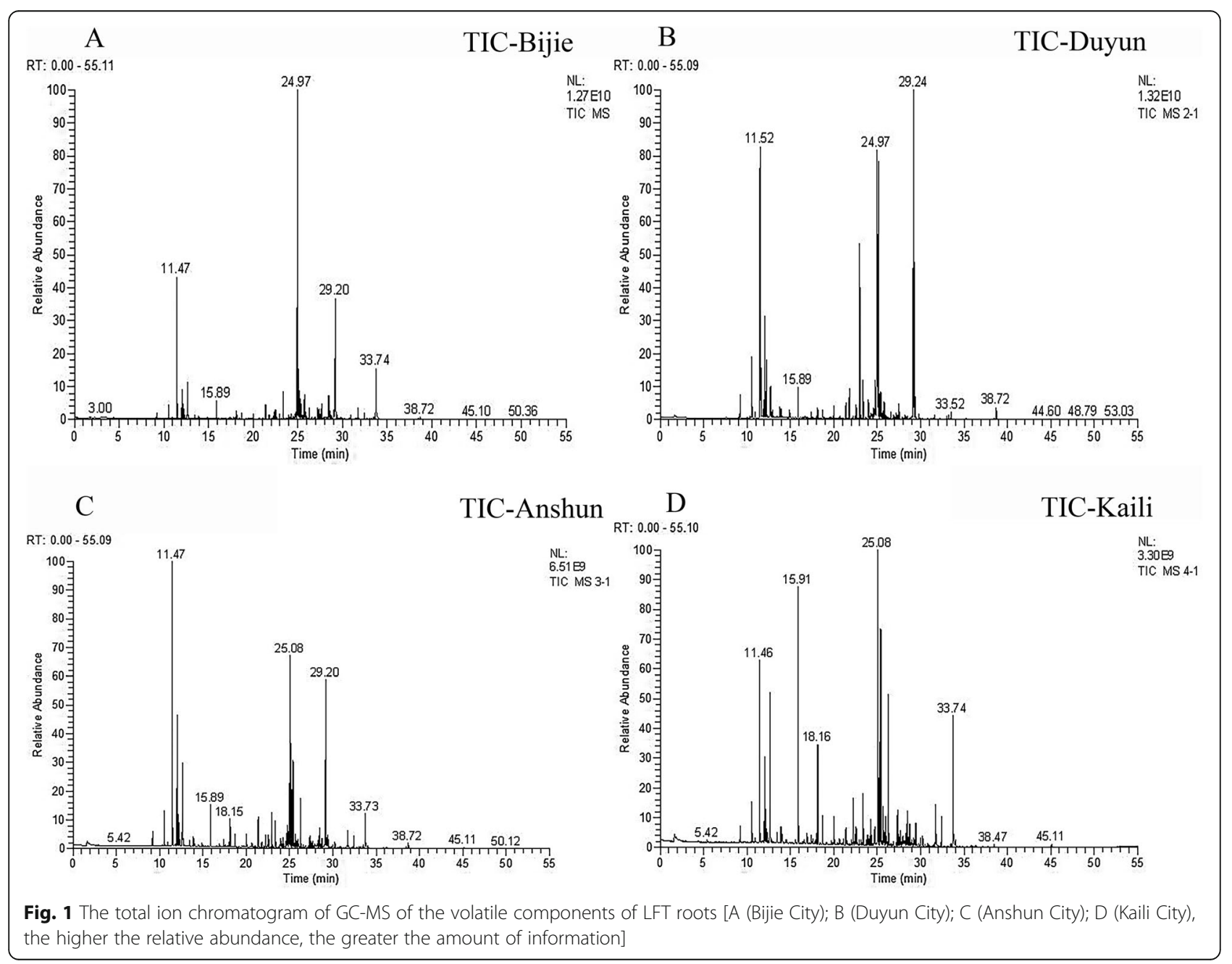




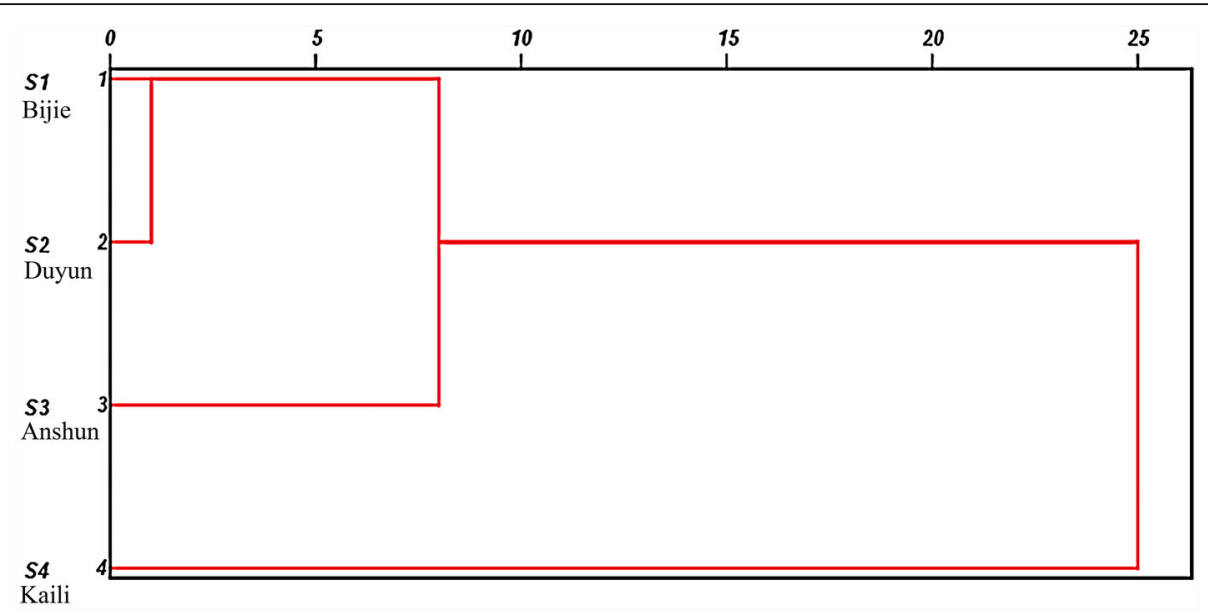

Fig. 2 CA of the volatile components of LFT roots [S1 (Bijie City); S2 (Duyun City); S3 (Anshun City); S4 (Kaili City), the closer the distance, the higher the sample similarity]
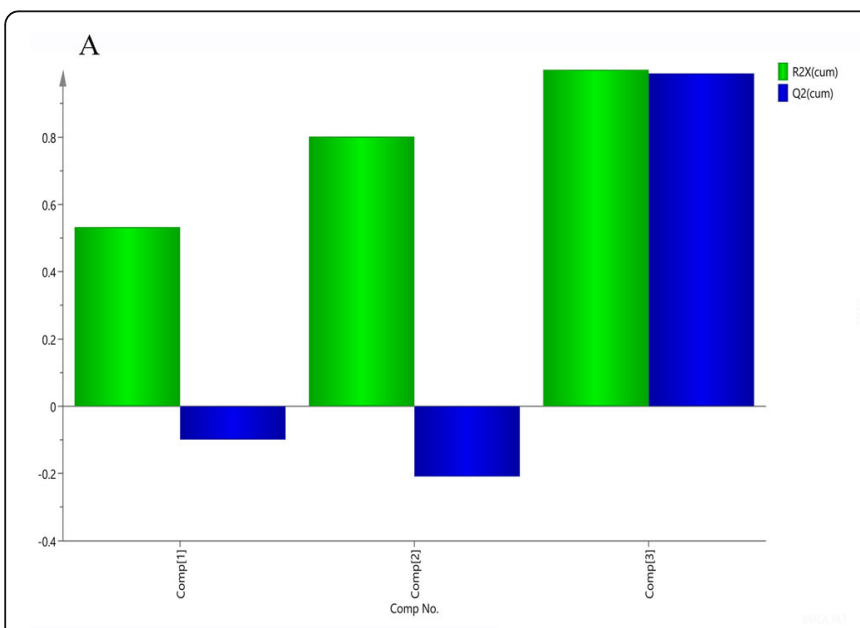

B
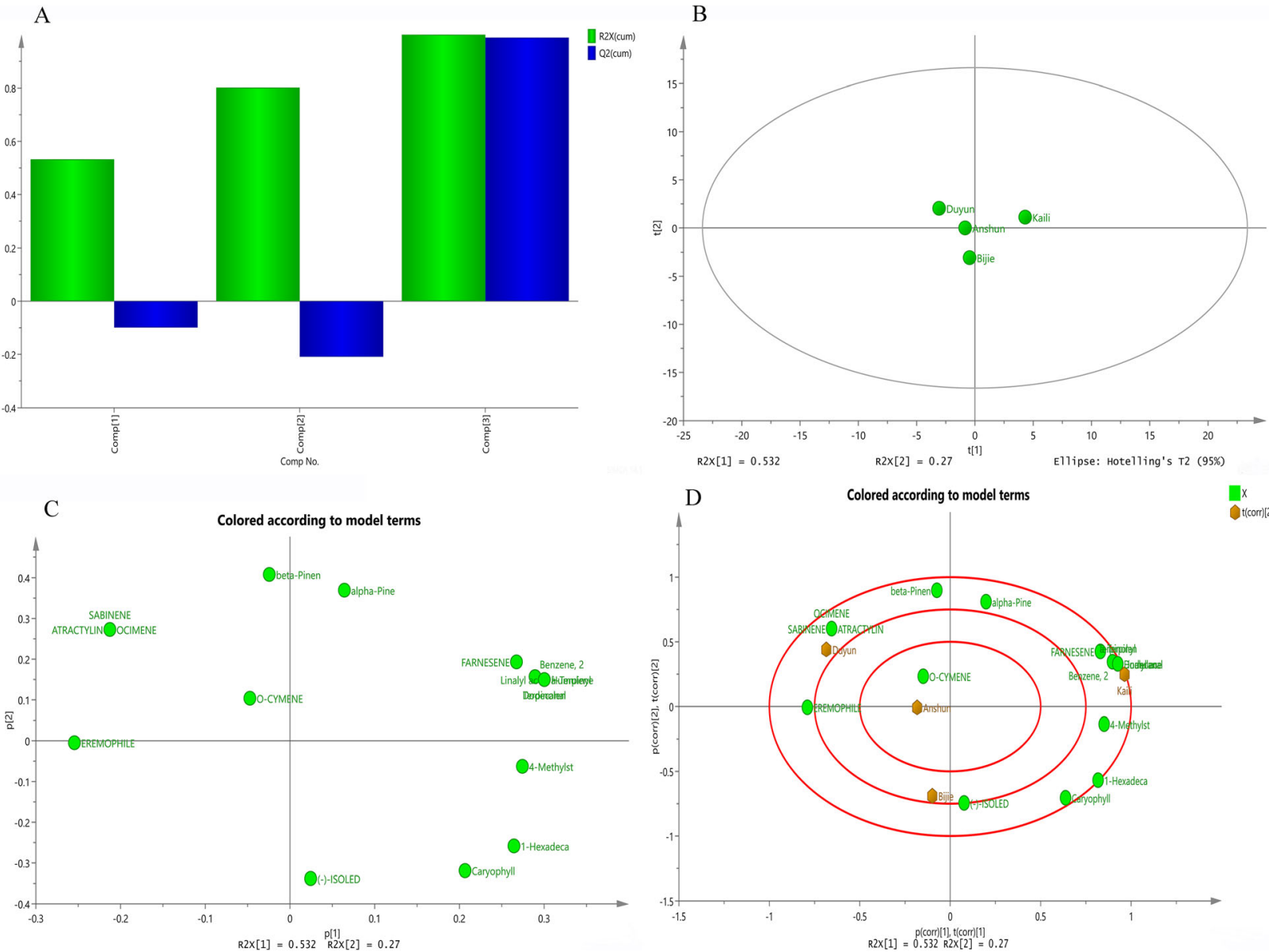

Fig. 3 Principal component analysis results of LFT roots (A: cumulative contribution rate, R2X and Q2 are greater than 0.8, indicating that the model is good.; B: score diagram, C: load diagram, the closer the sample is to the origin on the score diagram and load, the closer it is.; D: Bipolt diagram, the samples and volatile components are in the same quadrant of the Bipolt diagram, indicating that the two are more relevant) 
cymene, 4-methylstyrene, and caryophyllene. The 6, 11, 8, and 14 compounds were identified in LFT from four producing areas with percentage contents of 22.64, 25.45, 41.16, and $37.61 \%$, respectively. The main components of TIC in the sample from Bijie City, Guizhou Province, China were 4-methylstyrene (3.33\%), eremophilene (7.30\%), and 1-hexadecanol (4.99\%), among which alkenes and alcohols accounted for the highest proportion. The main components of TIC in the sample from Duyun City, Guizhou Province, China were O-cymene (3.45\%), sabinene $(2.53 \%)$, and eremophilene (11.21\%), among which alkenes showed the highest proportion. The main components of TIC in the sample from Anshun City, Guizhou Province, China were O-cymene (7.13\%), 4-methylstyrene (5.08\%), eremophilene (16.60\%), and farnesene (4.73\%), among which alkenes accounted for the highest proportion. The main components of TIC in the sample from Kaili City, Guizhou Province, China were O-cymene (3.38\%), 4-methylstyrene (6.17\%), farnesene (8.47\%), and 1-hexadecanol (5.37\%), among which alkenes and alcohols accounted for the highest proportion.

\section{Cluster analysis (CA)}

The percentage content of volatile components in all sample was standardized to form an $18 \times 4$ order original data matrix. CA was carried with SPSS 20.0 software. The intergroup connection method was used, and the Euclidean distance was used as the measure of the sample. According to the combination of correlation coefficients, the samples were divided into two groups; Bijie, Duyun, and Anshun were clustered into I, while Kali was clustered into II. The results are shown in Fig. 2.
PCA

To evaluate and synthetically analyze the volatile components of LFT in different growth environments, the percentage of volatile components in all samples were analyzed by PCA. Three principal components (PC1, PC2, PC3) were obtained. According to the variance contribution rate, the model's cumulative explanatory power parameter R2X, and predictive power parameter Q2 were 1.000 and 0.989 , respectively. These results show that the model has a good degree of discrimination and prediction. Therefore, the first three principal component analysis can reflect the main characteristics of the LFT. Using the principal components to establish a coordinate system, the PCA score diagram, a three-dimensional score diagram and load diagram of the samples were obtained. Each point on the load graph represents a variable; as distance from the origin increases, the content of the component makes a greater contribution to the classification. The results are shown in Fig. 3. The results revealed differences among the LFT samples, including some differences in chemical composition. According to the variable importance projection (VIP) value of the partial least square discriminate analysis model, the main chemical components leading to the differences were screened. The results are shown in Fig. 4. Variables with VIP $>1$ are considered to play a key role in classification. The VIP values of $O$-cymene (1.28), - (-)-isoledene (1.20), alpha-pinene (1.16), beta-pinene (1.15), sabinene (1.03), ocimene (1.03), atractyline (discontinued) (SH) (1.03), caryophyllene (1.02), and eremophilene (1.01) were all greater than 1 . Therefore, these chemical components were the main cause of the differences in the LFT.

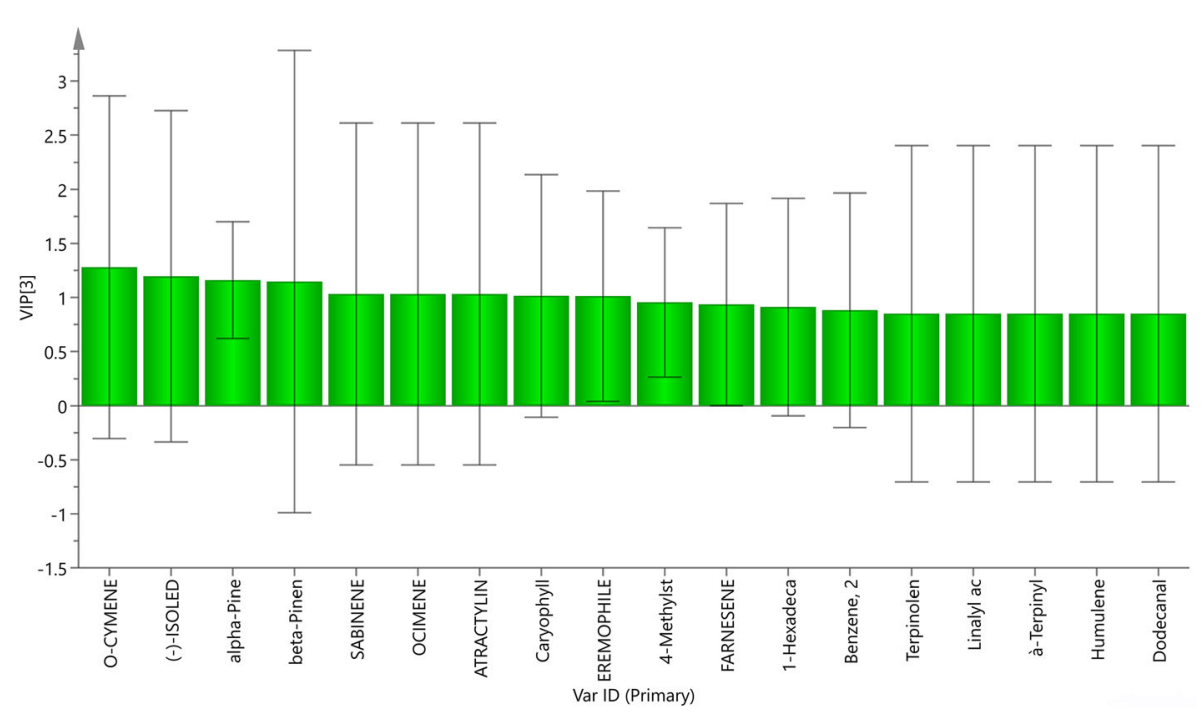

Fig. 4 VIP of different PLS-DA model markers of the volatile components of LFT roots (The VIP value is greater than 1, indicating that it is the main component) 


\section{Molecular structure and target protein prediction}

We aimed to evaluate the standard chemical composition of the four different producing areas of LFT. A total of 296 target proteins of the typical chemical constituents of LFT were obtained from the BATMAN-TCM database (Fig. 5). Two hundred inflammation-related target proteins were screened using the OMIM database.

\section{Network construction and screening of potential target proteins}

A "component-target-disease" network of the antiinflammatory effects of the LFT was constructed using disease-specific drug target analysis software. The network of visual analysis was prepared with Cytoscape 3.6.1 software. The results are shown in Fig. 6. Targets of drugs and diseases are represented by yellow squares, which are also the most critical target proteins for the anti-inflammatory effects of LFT.

The median of the three topological parameters (degree, betweenness centrality, and closeness centrality) of all nodes in the network was considered as the calculation result and had values of 3.000, 0.0049, and 0.1991, respectively. The topological parameter values of the 27 target proteins were all greater than the median mean. These targets were considered as potential target proteins of the anti-inflammatory effects of the volatile component. The results are shown in Table 2. Protein correlation analysis of the potential target proteins indicated that the potential target proteins of the antiinflammatory effects of the scorpion were correlated and regulated each other (Fig. 7). The results also revealed that the therapeutic effects of traditional Chinese medicine involve multiple targets.

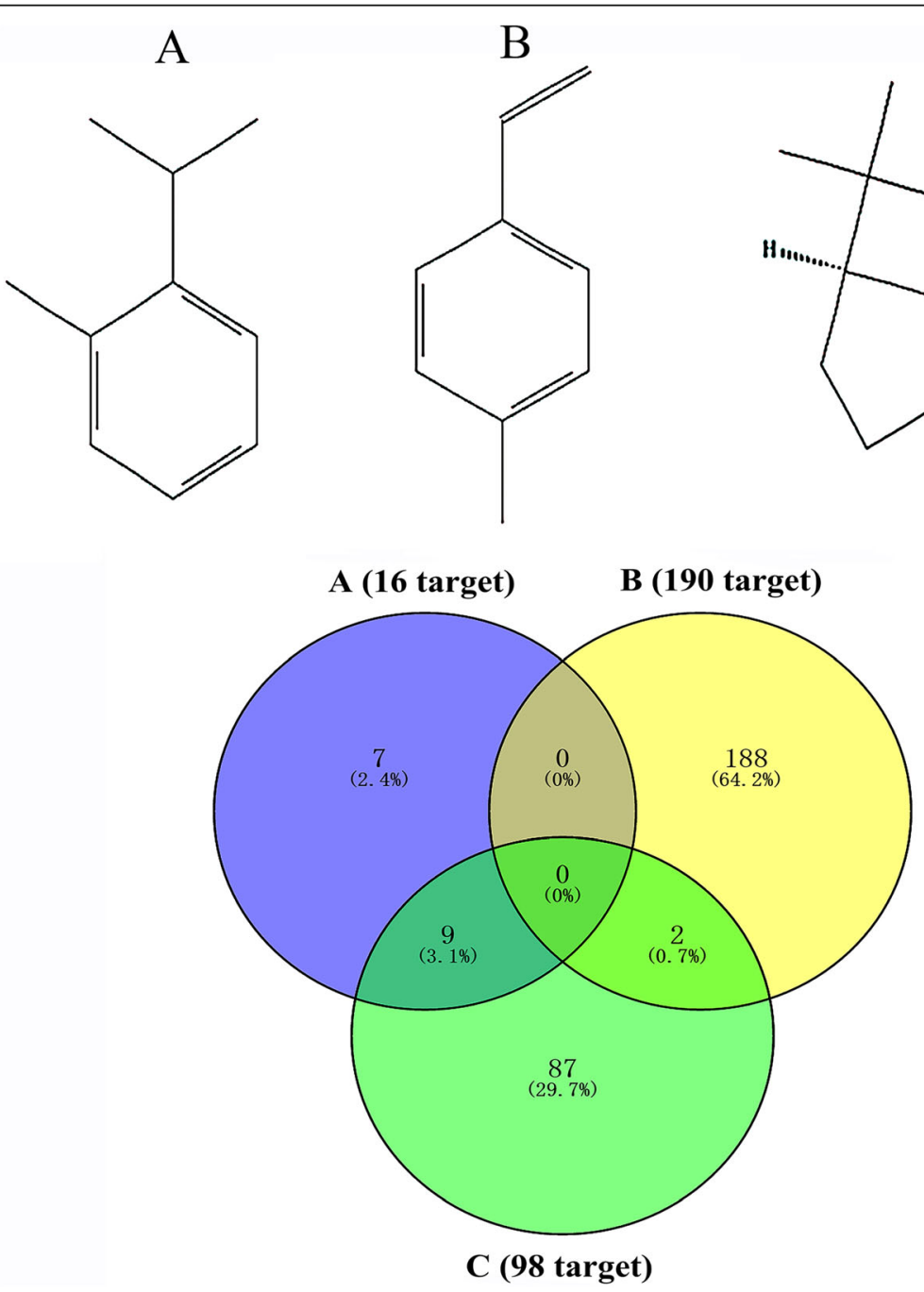

Fig. 5 Structure and target venny diagram of common chemical constituents of LFT roots [A: O-cymene (16 target); B: 4-methylstyrene (190 target); C: caryophyllene (98 target)] 


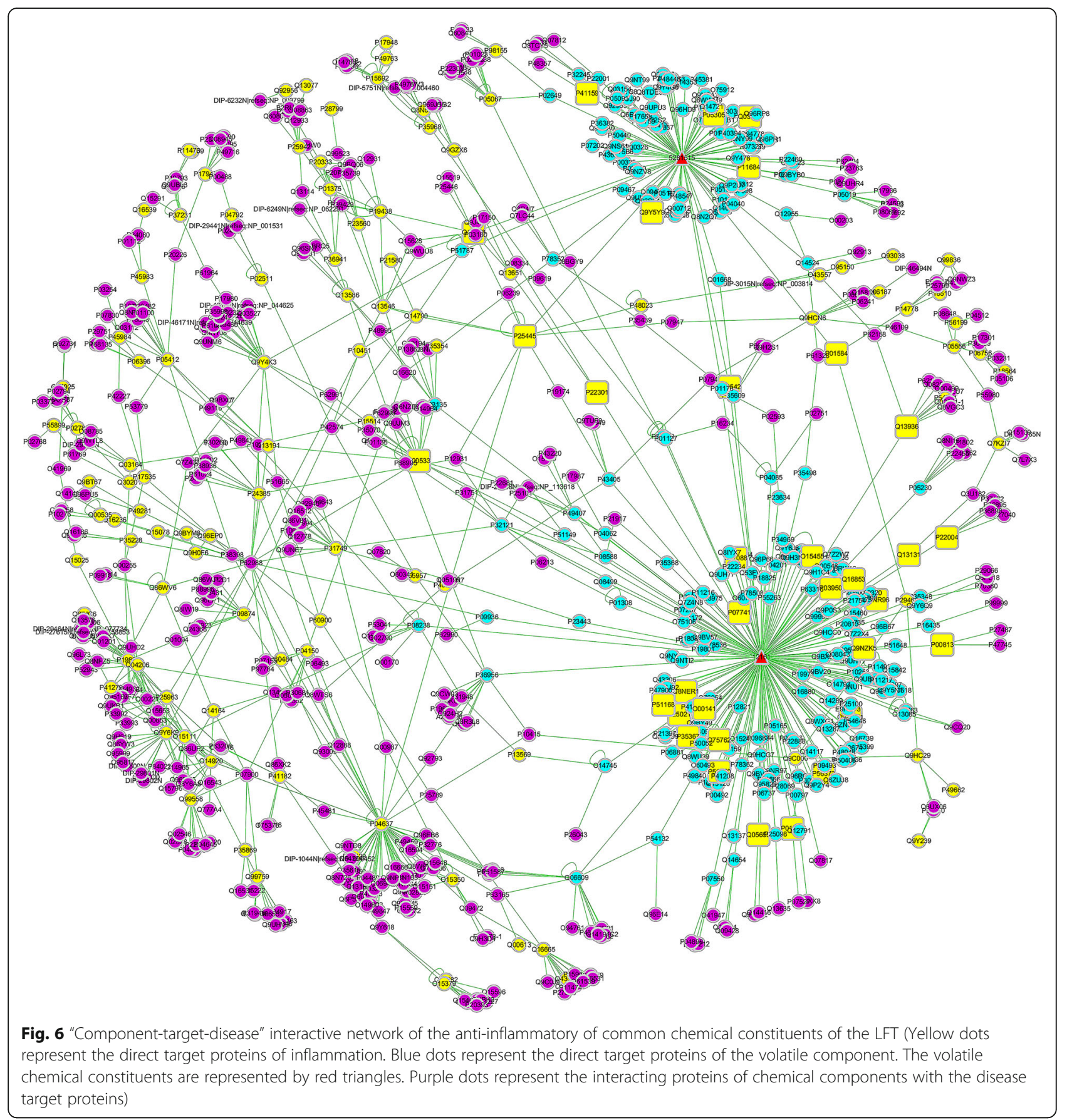

\section{GO and KEGG enrichment analysis results}

These potential target proteins underwent enrichment analysis of GO biological processes and KEGG pathways using the DAVID database (Fig. 8). GO enrichment analysis revealed 144 biological processes, 23 cell components, and 42 molecular functions, of which 65 biological processes had a $P$-value $\leq 0.01$. The results indicate that these targets are involved in various biological processes, including the positive regulation of $\mathrm{I}-\mathrm{kB}$ kinase/NF- $\mathrm{KB}$ signaling, positive regulation of transcription from RNA polymerase II promoter, TRIFdependent Toll-like receptor signaling pathway, cellular response to mechanical stimulus, I- $\kappa B$ kinase/NF- $\kappa B$ signaling, regulation of TNF-mediated signaling pathway, inflammatory response, activation of cysteine-type endopeptidase activity involved in apoptotic signaling pathway, and positive regulation of NF- $\mathrm{kB}$ transcription factor activity. These biological processes may be closely related to the occurrence and development of inflammation and that the onset of inflammation 
Table 2 Related parameters of potential target proteins of t LFT roots

\begin{tabular}{|c|c|c|c|c|c|c|}
\hline Uniprot ID & PDB ID & Gene names & Protein names & Betweenness Centrality & Closeness Centrality & Degree \\
\hline P41182 & 6CQ1 & $\mathrm{BCL6}$ & B-cell lymphoma 6 protein & 0.0340 & 0.2275 & 8 \\
\hline P24385 & 1019 & CCND1 & G1/S-specific cyclin-D1 & 0.0277 & 0.2442 & 10 \\
\hline P25963 & 3BRT & NFKBIA & NF-kappa-B inhibitor alpha & 0.0420 & 0.2350 & 18 \\
\hline 015111 & $5 E B Z$ & CHUK & $\begin{array}{l}\text { Inhibitor of nuclear factor kappa-B } \\
\text { kinase subunit alpha }\end{array}$ & 0.0221 & 0.2191 & 18 \\
\hline 014920 & $4 \mathrm{KIK}$ & IKBKB & $\begin{array}{l}\text { Inhibitor of nuclear factor kappa-B } \\
\text { kinase subunit beta }\end{array}$ & 0.0147 & 0.2181 & 15 \\
\hline Q14164 & $6 \mathrm{AKK}$ & IKBKE & $\begin{array}{l}\text { Inhibitor of nuclear factor kappa-B } \\
\text { kinase subunit epsilon }\end{array}$ & 0.0051 & 0.2134 & 5 \\
\hline P05412 & 1JNM & $J U N$ & Transcription factor AP-1 & 0.0504 & 0.2078 & 13 \\
\hline Q99558 & $6 \mathrm{G} 4 \mathrm{Z}$ & MAP 3 K14 & $\begin{array}{l}\text { Mitogen-activated protein kinase } \\
\text { kinase kinase } 14\end{array}$ & 0.0172 & 0.2014 & 13 \\
\hline Q9Y6K9 & 3BRV & IKBKG & NF-kappa-B essential modulator & 0.0558 & 0.2371 & 23 \\
\hline Q16236 & $2 L Z 1$ & NFE2L2 & Nuclear factor erythroid 2-related factor 2 & 0.0074 & 0.2259 & 4 \\
\hline P04637 & $3 \mathrm{DCY}$ & TP53 & Cellular tumor antigen p53 & 0.2135 & 0.2641 & 60 \\
\hline P09874 & $5 X S R$ & PARP1 & Poly [ADP-ribose] polymerase 1 & 0.0290 & 0.2129 & 11 \\
\hline Q86WV6 & $6 \mathrm{CY} 7$ & TMEM173 & Stimulator of interferon genes protein & 0.0089 & 0.2285 & 8 \\
\hline Q04206 & $3 Q X Y$ & RELA & Transcription factor p65 & 0.0207 & 0.2033 & 19 \\
\hline P19438 & $5 X M E$ & TNFRSF1A & $\begin{array}{l}\text { Tumor necrosis factor receptor superfamily } \\
\text { member } 1 \mathrm{~A}\end{array}$ & 0.0151 & 0.2131 & 11 \\
\hline Q13546 & $6 \mathrm{NW} 2$ & RIPK1 & $\begin{array}{l}\text { Receptor-interacting serine/threonine- } \\
\text { protein kinase } 1\end{array}$ & 0.0622 & 0.2541 & 7 \\
\hline Q9Y4K3 & 1LB5 & TRAF6 & TNF receptor-associated factor 6 & 0.0774 & 0.2721 & 22 \\
\hline Q14790 & 2LR8 & CASP8 & Caspase-8 & 0.0165 & 0.2160 & 6 \\
\hline P48023 & 2NA6 & FASLG & $\begin{array}{l}\text { Tumor necrosis factor ligand superfamily } \\
\text { member } 6\end{array}$ & 0.0098 & 0.2033 & 4 \\
\hline Q13191 & 2LDR & CBLB & E3 ubiquitin-protein ligase CBL-B & 0.0074 & 0.2479 & 5 \\
\hline Q13586 & $409 B$ & STIM1 & Stromal interaction molecule 1 & 0.0074 & 0.2116 & 7 \\
\hline P31749 & $4 \mathrm{EKL}$ & AKT1 & RAC-alpha serine/threonine-protein kinase & 0.0312 & 0.2519 & 13 \\
\hline P22004 & $60 \mathrm{MO}$ & BMP6 & Bone morphogenetic protein 6 & 0.0098 & 0.2416 & 5 \\
\hline Q13936 & $6 \mathrm{DAD}$ & CACNA1C & $\begin{array}{l}\text { Voltage-dependent L-type calcium channel } \\
\text { subunit alpha-1C }\end{array}$ & 0.0194 & 0.2426 & 9 \\
\hline P00533 & $3 \mathrm{~W} 2 \mathrm{~S}$ & EGFR & Epidermal growth factor receptor & 0.0955 & 0.2920 & 20 \\
\hline Q13158 & 2GF5 & FADD & FAS-associated death domain protein & 0.0203 & 0.2333 & 8 \\
\hline P25445 & 2JFD & FAS & $\begin{array}{l}\text { Tumor necrosis factor receptor superfamily } \\
\text { member } 6\end{array}$ & 0.1111 & 0.2545 & 12 \\
\hline
\end{tabular}

involves up-and-down regulation of multiple biological processes in the human body. The results also suggest that the volatile components in LFT exert antiinflammatory effects by regulating these biological processes.

A total of 65 signal pathways were obtained by KEGG pathway enrichment analysis, of which 50 signal pathways showed a P-value $\leq 0.01$. Thus, volatile components in LFT may be involved many important signaling pathways, such as apoptosis, TNF signaling pathway, herpes simplex infection, RIG-I-like receptor signaling pathway, Toll-like receptor signaling pathway, pathways in cancer, MAPK signaling pathway, Epstein-Barr virus infection, chronic myeloid leukemia, small cell lung cancer, NF- $\mathrm{kB}$ signaling pathway, epithelial cell signaling in Helicobacter pylori infection, toxoplasmosis, HTLV-I infection, NOD-like receptor signaling pathway, and $\mathrm{T}$ cell receptor signaling pathway. These signaling pathways may directly or indirectly participate in the anti-inflammatory effects of LFT and may be closely related to the pathogenesis of inflammation. These results also reveal the therapeutic effect of traditional Chinese medicine on multi-components and multi-targets. 


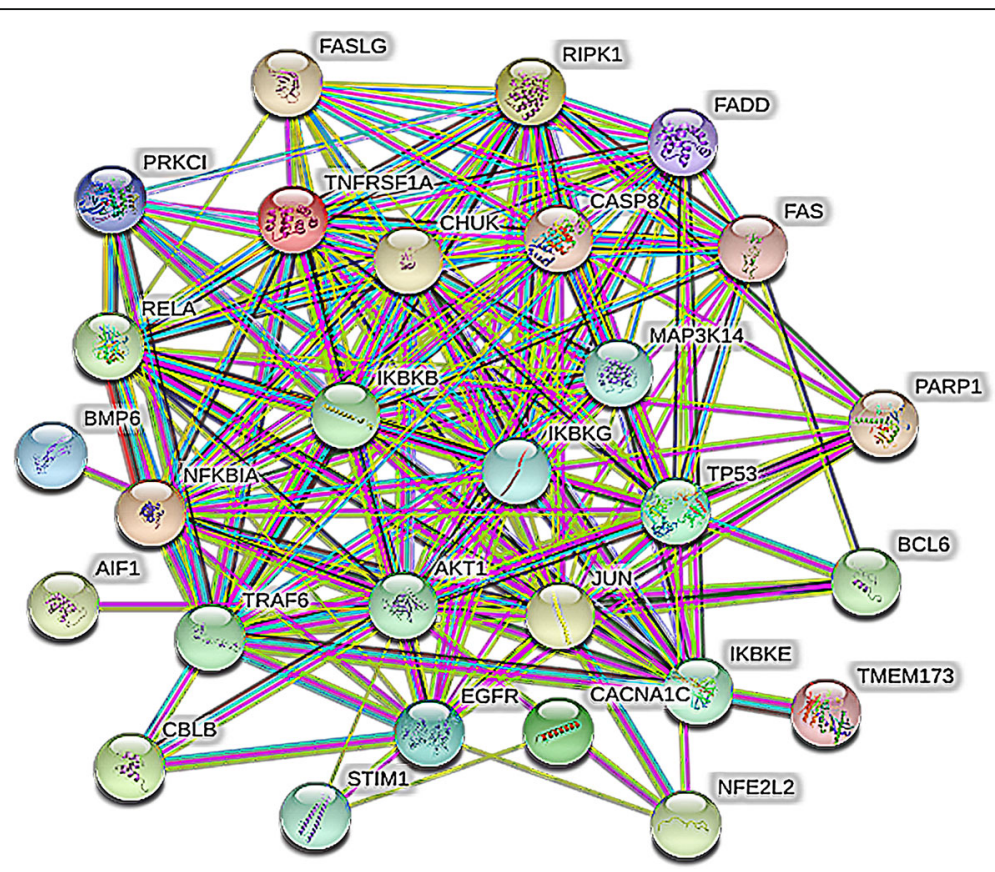

Fig. 7 Interaction diagram of potential target proteins of LFT roots (The more connections between proteins, the more important it is)

\section{Docking results}

In this study, molecular docking was performed using the potential target proteins as research objects and was carried out using the SystemsDock website to verify the affinity of these target proteins with small-molecule compounds. A system docking score higher than 4.25 indicates binding activity between the docking molecule and target protein, greater than 5.00 indicates better binding activity, and greater than 7.00 indicates strong binding activity [21]. The molecular docking results showed that the system docking scores of the identified components and 27 target proteins were higher than 5.0 (Fig. 9).

\section{Discussion}

The contents of volatile components in LFT from different producing areas show apparent differences. The quality of traditional Chinese medicine depends not only on its genetic characteristics but also on its ecological environment and cultivation methods [22]. Therefore, differences in the volatile components of TIC may be closely related to the growth environment (such as soil, temperature, humidity, etc.) and genetic characteristics.

The compounds identified the LFT were mainly alkenes, followed by phenols, aldehydes, and alcohols, which are characteristic components of the LFT. Some volatile components had distinct biological activities and pharmacological functions. For example, $\mathrm{Li}[23,24]$ showed that $\alpha$-pinene and $\beta$ pinene have antispasmodic, expectorant, and antibacterial effects. It has been reported that caryophyllene oxide has analgesic, anti-inflammatory, and antifungal effects [25].
CA showed that the volatile components of the sample from Kaili greatly differed from samples from the other three locations. These four producing areas differ in geographical location, altitude, and climate. Therefore, the differences in samples may be closely related to the growth environment (such as soil, temperature, humidity, etc.) and genetic characteristics.

In the present work, except for the samples from Kaili, the samples were concentrated in the principal component space. The volatile components of the samples from Kaili and other regions significantly differed. This may be because of differences in the geographical environment and climatic conditions, resulting in the accumulation of different chemical components and contents. Populations from geographically close regions showed similar distributions of principal components, suggesting that attention should be given to the influence of environmental modification on the quality of LFT.

The results of GO enrichment analysis indicated that the LFT potential targets are mainly regulated by positive regulation of $\mathrm{I}-\mathrm{kB}$ kinase/NF- $\mathrm{kB}$ signaling, positive regulation of transcription from RNA polymerase II promoter, TRIF-dependent Toll-like receptor signaling pathway, cellular response to mechanical stimulus, $I-\kappa B$ kinase/NF- $\mathrm{BB}$ signaling, regulation of TNF-mediated signaling pathway, and inflammatory response. Biological processes have an anti-inflammatory role. These biological processes are closely related to the occurrence and development of inflammation. KEGG signaling pathway enrichment analysis showed that LFT mainly 


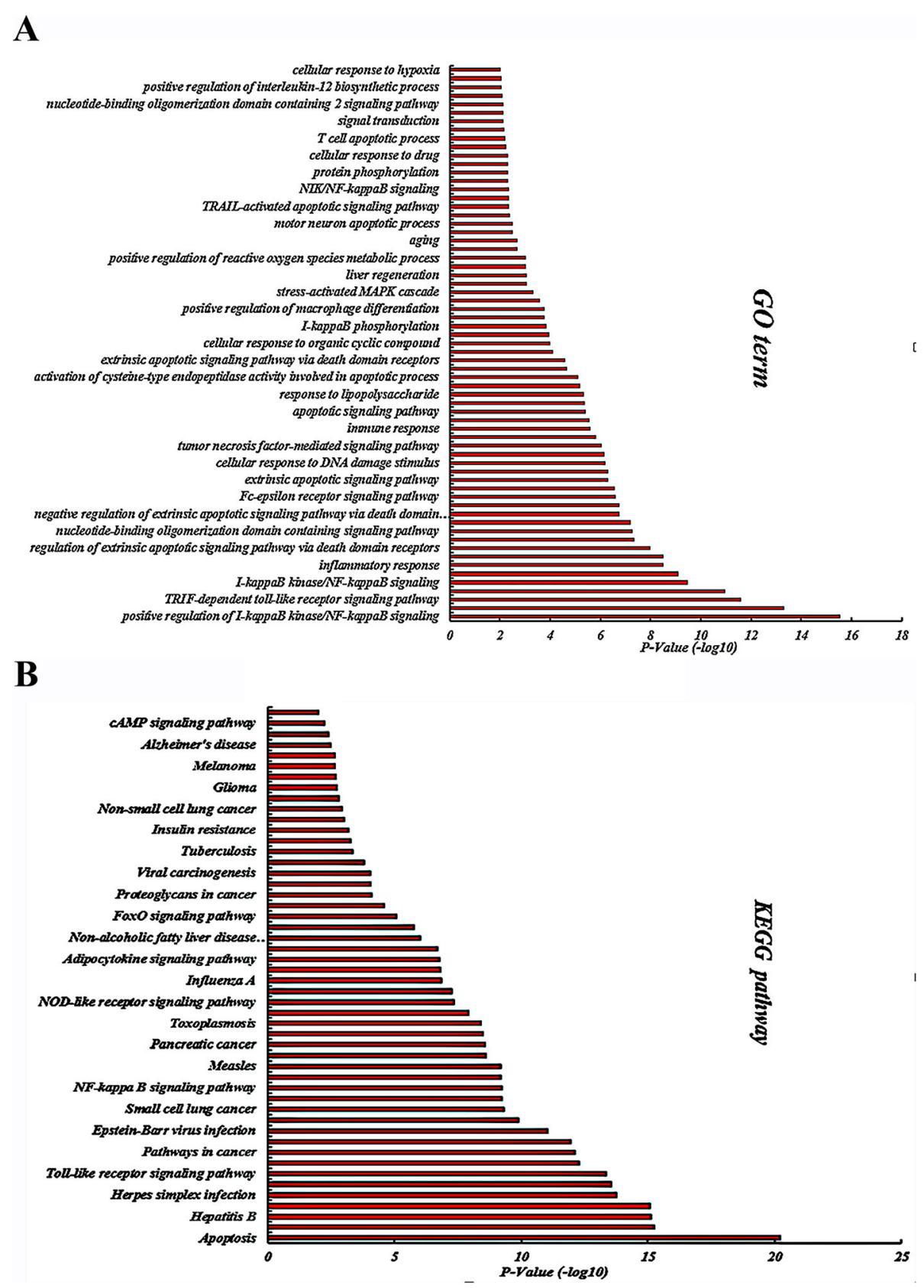

Fig. 8 The functional analysis of potential target proteins of LFT roots (A: GO terms; B: KEGG pathway, P-value $\leq 0.01$, the smaller the P-value, the higher the significance)

exerts synergistic anti-inflammatory effects via TNF signaling pathway, herpes simplex infection, RIG-I-like receptor signaling pathway, Toll-like receptor signaling pathway, pathways in cancer, MAPK signaling pathway. Molecular docking showed that these chemical components have high binding activity to the predicted target protein and that the anti-inflammatory effects of volatile components of LFT are closely related to these targets. Studies have also confirmed that these signaling pathways are closely related to inflammation. Constructing an interactive network diagram of "component-targetdisease" by network pharmacology analysis, it will provide a foundation for further studies of the antiinflammatory effects of the LFT.

\section{Conclusion}

In summary, our study found significant variability in the volatile components of the different habitats of LFT analysed, confirmed by the similarity analysis, the hierarchical clustering analysis, and the principal component analysis. 

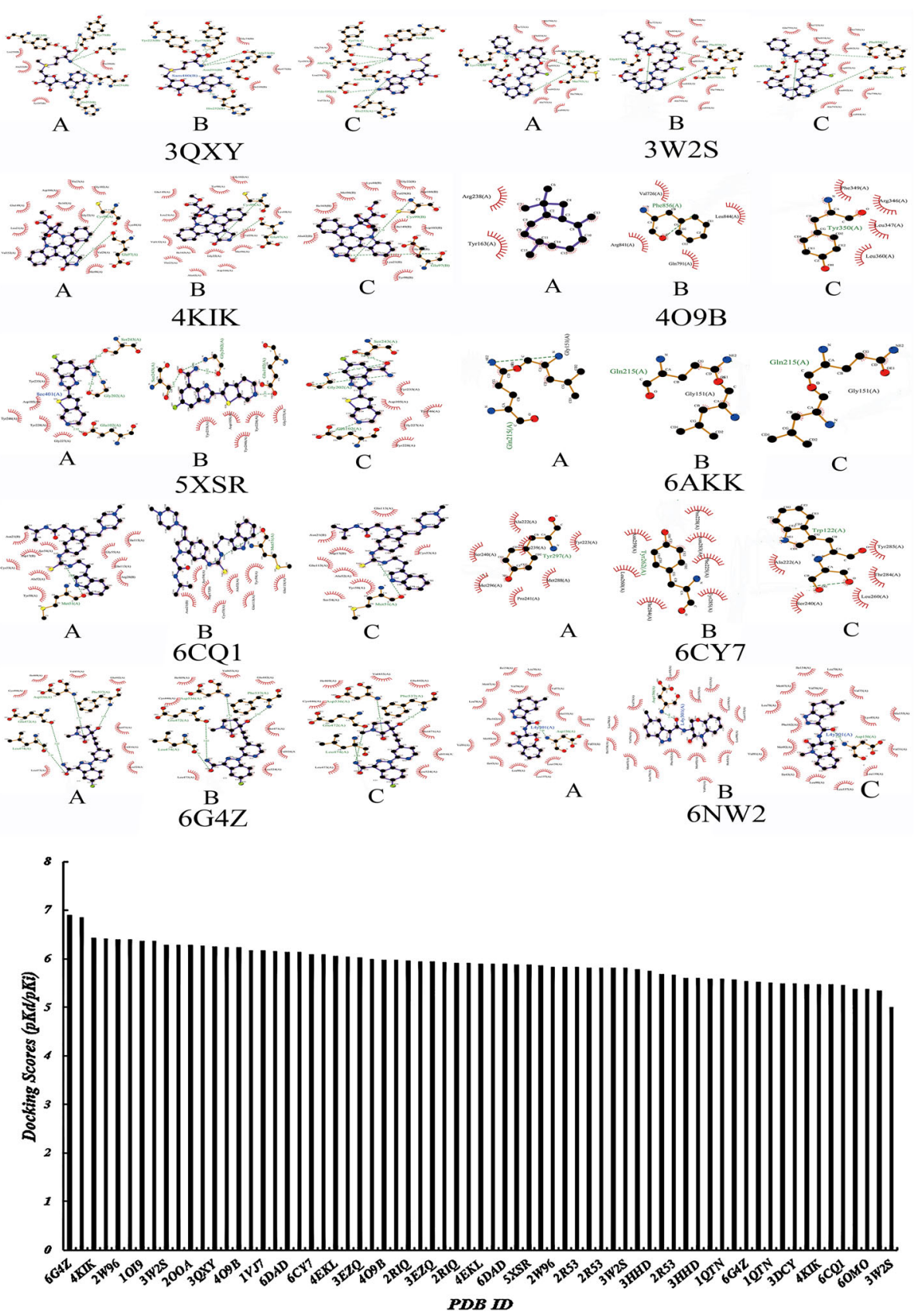

Fig. 9 Molecular docking results of LFT roots (A: caryophyllene; B: 4-methylstyrene; C: O-cymene, the docking score higher than 4.25 indicates binding activity between the docking molecule and target protein, greater than 5.00 indicates better binding activity, and greater than 7.00 indicates strong binding activity)

The obtained results by SPME-GC/MS indicated that different chromatographic profiles for the four LFT samples, leading to the conclusion that factors such as the climatic conditions, the storage conditions and the different geographic origin of the samples may contribute to such variability. The present study revealed potential mechanism regarding the anti-inflammatory effect of volatile components in LFT by network pharmacology and molecular docking analyses. The results proved that inhibiting the production of inflammatory factors might play a key role in the anti-inflammatory effects of volatile component of LFT. This study not only explored the molecular mechanisms of the anti-inflammatory effect of volatile components in LFT, which laid the foundation for further investigation, but also presented novel clues for the development and utilization of LFT resources. 


\section{Abbreviations}

CA: Cluster analysis; GC-MS: Gas chromatography-mass spectrometry; HSSPME: Headspace solid-phase microextraction; IL-6: Interleukin; LFT: Ligularia fischeri (Ledeb) turcz; PCA: Principal components analysis; SPME-GC/ MS: Headspace solid-phase microextraction-gas chromatography-mass spectrometry; TIC: The total ion chromatogram; TNF-a: Tumor necrosis factor -a

\section{Acknowledgments}

We would like to thank Prof. Xiangpei Wang from Guizhou University of Traditional Chinese Medicine for help in GC-MS experiment.

\section{Authors' contributions}

The individual contributions are as follows: conceptualization, X.W. and H.W.; methodology, F.X.; software, Y.L.; validation, Y.G.; formal analysis, D.F.; investigation, X.H.; resources, F.X.; data curation, X.H.; writing —original draft preparation, X.H.; writing-review and editing, X.W.; visualization, Y.G.; supervision, F.X.; project administration, H.W.; funding acquisition, X.W. All authors have read and approved the manuscript.

\section{Funding}

This research was funded by the Guizhou domestic first-class construction project [(Chinese Materia Medica) (GNYL [2017] 008)], Guizhou Province Miao Medicine key Laboratory Project [Qianmiao medicine K Zi [2017] 027], and Miao Nationality Medicine Research Synergy Innovation Center Project (Grant No. Qian Jiao He Xie Tong Chuang Xin Zi [2015] 05th). The funding bodies play no role in the design of the study and collection, analysis, and interpretation of data and in writing the manuscript.

\section{Availability of data and materials}

All data generated or analyzed during this study are included in this published article.

\section{Ethics approval and consent to participate}

Not applicable.

\section{Consent for publication}

Not applicable.

\section{Competing interests}

The authors declare no conflict of interest.

\section{Author details}

${ }^{1}$ Department of Pharmacy, Guizhou University of Traditional Chinese Medicine, Guiyang City, Guizhou Province, Guiyang 550002, People's Republic of China. 'Department of Food, Guizhou Food and Drug Inspection Institute, Guiyang City, Guizhou Province, Guiyang 550002, People's Republic of China. ${ }^{3}$ Pharmacy, The First Affiliated Hospital of Guizhou University of Traditional Chinese Medicine, Guizhou Province, Guiyang 550002, People's Republic of China. ${ }^{4}$ Department of Pharmacy, Zunyi Medical and Pharmaceutical College, Zunyi City, Guizhou Province, Zunyi 563000, People's Republic of China.

Received: 19 August 2019 Accepted: 12 February 2020

Published online: 10 April 2020

\section{References}

1. Zhao Y, Yang R, Wang CF. Chemical constituents from the rhizomes of Ligularia vellerea. Nat Prod Res Dev. 2014;26:340-4.

2. Xiao PG. Records of Chinese Materia Medica. Beijing: People's Medical Publishing House; 1982.

3. Wang XL, Li Q, Yang YJ, Zhai HY. Study on the composition and activity of volatile oil from Ligularia genus. J Chin Med Mater. 2014;37:1005-11.

4. Shimizu A, Suzuki Y, Hanai R. Chemical and genetic similarity and diversity of Ligularia anoleuca and L fischeri collected in the Hengduan Mountains of China. Phytochemistry. 2014;102:137-44

5. Lee KH, Choi EM. Analgesic and anti-inflammatory effects of Ligularia fischeri leaves in experimental animals. J Ethnopharmacol. 2008;120:103-7.

6. Kim Y, Kim JT, Park J. 4, 5-Di-O-Caffeoylquinic acid from Ligularia fischeri suppresses inflammatory responses through TRPV1 activation. Phytother Res. 2017;31:1564-70.
7. Hong S, Joo T, Jhoo JW. Antioxidant and anti-inflammatory activities of 3, 5dicaffeoylquinic acid isolated fromligularia fischeri leaves. Food Sci Biotechnol. 2015;4:257-63.

8. Wang XL, Li Q, Yang YJ. Studies on the constituents and activities of volatile oil from Ligularia. China J Chin Materia Medica. 2014;37:1005-11.

9. Ran D, Minlun N, Zhang HL. Analysis of chemical composition of leaf volatile oils from two species of Ligularia genus from Changbai Mountai. Food Sci. 2010;31:228-30.

10. Xiang LP, Xiao YM, Hui SP. Analysis of Liposoluble constituents from Ligularia fischeri by GC-MS. Lishizhen Med Materia Medica Res. 2009;20: 2410-1.

11. Xiao WM, Mu QS, Hong XW. Analysis of the volatile profile of Core Chinese mango Germplasm by headspace solid-phase microextraction coupled with gas chromatography-mass spectrometry. Molecules. 2018;23:1480.

12. Chua LY, Chong CH, Chua BL, Figiel A. Influence of drying methods on the antibacterial, antioxidant and essential oil volatile composition of herbs: a review. Food Bioprocess Technol. 2019;12:1-27.

13. Han WJ, Cheng K, Wang Y. Anti-inflammatory mechanism of Ligularia alcoholization ethyl acetate extract. China J Mod Med. 2015;25:6-10.

14. Chai XY, Wu DS, Zhao DQ. Study on Analgesic and Anti-inflammatory Activity of Extract from Ligularia dictyoneura (Franch.) Hand.-Mazz. J Yunnan Univ Tradit Chin Med. 2018:6:1-5.

15. Michalak PB, Filipek A, Chomicki P, Woźniak MZ, Monika KA. Lignans from Forsythia $\mathrm{x}$ Intermedia leaves and flowers attenuate the pro-inflammatory function of leukocytes and their interaction with endothelial cells. Front Pharmacol. 2018:9:401.

16. Wen $Y Z$, Wen DH, Gui YL. Tgr5 induces il-1 $\beta$, tnf- $\alpha$ and il-6 mRNA transcription by p38 mapk pathway in mouse macrophages. J Third Mil Med Univ. 2012;7:597-601.

17. Katsiari CG, Bogdanos DP, Sakkas LI. Inflammation and cardiovascular disease. World J Transl Med. 2019:8:1-8.

18. Marco DB, Antonio A, Stefano T. Interplay of inflammation, oxidative stress and cardiovascular disease in rheumatoid arthritis. Heart. 2018;104:1987-8.

19. Alexandros $T$, Ronan $L$, loannis $Z$. Inflammation, not cholesterol, is a cause of chronic disease. Nutrients. 2018:10:604.

20. Xie J, Gao S, Li L, Xu YL. Research progress and application strategy on network pharmacology in Chinese materia medica. Chin Tradit Herb Drugs. 2019;10:2257-64.

21. Hsin KY, Matsuoka Y, Asai Y, Kamiyoshi K, Watanabe T. SystemsDock: a web server for network pharmacology-based prediction and analysis. Nucleic Acids Res. 2016;44:507-13.

22. Zhang TJ, Bai G, Liu CX. The concept, core theory and research methods of Chinese medicine quality markers. Acta Pharm Sin. 2019;6:187-96.

23. Li XJ, Zhao JY, Chen Y. Analysis of chemical constituents of petroleum ether extract of Ligularia polyphylla. Jilin Agric. 2017;9:62-3.

24. Li YH, Li QM, Huang ZF. GC simultaneous determination of the contents of seven constituents in volatile oil from Houttuyniae Herba. Chin J Pharm Anal. 2015;35:1810-4.

25. XY LI, Cao CL, Wu JK. Analysis on volatile components of two kinds of Magnolia flowers by head-space gas chromatography-mass spectrometry. J Food Sci Technol. 2017;35:53-60.

\section{Publisher's Note}

Springer Nature remains neutral with regard to jurisdictional claims in published maps and institutional affiliations.

\section{Ready to submit your research? Choose BMC and benefit from:}

- fast, convenient online submission

- thorough peer review by experienced researchers in your field

- rapid publication on acceptance

- support for research data, including large and complex data types

- gold Open Access which fosters wider collaboration and increased citations

- maximum visibility for your research: over $100 \mathrm{M}$ website views per year

At BMC, research is always in progress.

Learn more biomedcentral.com/submissions 